\title{
THE EFFECT OF TESTOSTERONE AND ALLIED COMPOUNDS ON THE MINERAL, NITROGEN, AND CARBOHYDRATE METABOLISM OF A GIRL WITH ADDI- SON'S DISEASE 1, 2
}

\author{
By NATHAN B. TALBOT, ALLAN M. BUTLER, and E. A. MacLACHLAN \\ (From the Department of Pediatrics, Harvard Medical School, The Children's Medical Service, \\ Massachusetts General Hospital, and the Infants' and Children's Hospitals, Boston)
}

(Received for publication January 14, 1943)

\section{INTRODUCTION}

The evidence of the literature indicates that the adrenal cortex produces a variety of hormones, some of which, like desoxycorticosterone, act predominantly to maintain a normal water and electrolyte balance (1), while others, like corticosterone, are effective chiefly through preventing hypoglycemia, either by facilitating the formation of sugar from protein (gluconeogenesis) (2) or by inhibiting utilization of sugar by the tissues (3). Up to the present, most replacement therapy for patients with adrenal cortical insufficiency has been concerned with these two types of adrenal hormones. There is, however, clinical and experimental evidence that the adrenal cortex also secretes other types of hormones, some of which are androgenic $(4,5)$. Recent evidence has shown that such androgens not only prompt masculine secondary sexual development, but also an increase in muscular mass and endurance (6, 7). A striking example of this phenomenon is provided by the Herculean development of certain children with virilism due to hyperplasia or carcinoma of the adrenal cortex (8). These individuals usually excrete abnormally large quantities of neutral urinary 17 -ketosteroids $(9,10)$ which are believed to be excretory transformation products of the adrenal cortical and, to a lesser extent, of the testicular androgens $(9,11)$.

A striking example of the effect of adrenal cortical androgens upon a patient with adrenal cortical insufficiency is provided by a boy with congenital adrenal cortical hyperplasia, elevated

1 This work was supported by a grant from The Commonwealth Fund, New York.

2 The authors are indebted to Drs. Max Gilbert and Erwin Schwenk of The Schering Corporation, N. J. for supplies of testosterone, anhydro-hydroxy-progesterone, and methyl androstenediol. 17-ketosteroid excretion, macrogenitosomia without enlargement of the testes, and the disturbances of salt and water metabolism characteristic of Addison's disease (12). When this patient is receiving adequate doses of desoxycorticosterone or of sodium chloride, he is remarkably strong and energetic (13).

In contrast to this patient and to individuals with simple adrenal cortical virilism, most patients with adrenal cortical insufficiency (Addison's disease) fatigue easily, are weak (14) and excrete abnormally small quantities of urinary 17 ketosteroids (11). The fact that certain Addisonian patients still lack energy and endurance when receiving adequate doses of desoxycorticosterone acetate and salt $(14,15)$ suggests that other therapy may be needed to restore such patients to normal.

The present paper explores the possibility that androgen therapy may be beneficial for such Addisonian patients. An 8-year-old girl patient with moniliasis and severe Addison's disease was selected for this study. Details concerning her clinical history will be reported separately. The results of the present investigation are presented in four sections: (1) measurements of weight, nitrogen balance, blood sugar concentrations, and 17-ketosteroid output over a period of 300 days; (2) observations on the potassium and nitrogen metabolism and body weight; (3) certain observations on the disturbance in calcium and phosphorus metabolism which resulted from an idiopathic hypoparathyroidism which appeared to be superimposed upon the Addison's disease; and (4) clinical changes noted during the course of the study.

\section{METHODS}

For 6 days before the study was started and during the first 131 days of the study (Figure 1 , period 1 to first 
half of period 9), the patient was placed on a ward reserved for children with metabolic diseases at the Children's Hospital. While there, she received 6 grams of sodium chloride daily and a constant weighed diet, which upon analysis was found to contain 6.4 grams of nitrogen per day. From the 132nd to the 300th day of the investigation (Figure 1, second half of period 9 through period 18), the patient lived on the metabolism ward of the Massachusetts General Hospital. The weighed diet which she received there was repeated every 3 days. It was calculated to contain 7.7 grams of nitrogen, 2.8 grams of potassium, 0.8 gram of sodium, 0.85 gram of calcium, and 1.1 grams of phosphorus per day. In addition, 9 grams of sodium chloride were added to the diet daily. Her physical activity throughout the period of study was consistently very moderate.

During the first five 3-day periods at the Children's Hospital, the fecal nitrogen excretion was determined. This was found to be consistently 0.5 gram per day or 8 per cent of the nitrogen intake. Testosterone therapy did not alter this stool to dietary nitrogen ratio. Thereafter, stool analyses were omitted and in calculations of the nitrogen balance, the nitrogen lost in the stools was taken as 8 per cent of the intake.

The urine was collected daily with $5 \mathrm{cc}$. toluene as preservative. During periods when urea, creatinine, and creatine were measured, the urine was stored in the refrigerator. Prior to most analyses, the urine was pooled in 3-day batches which corresponded in point of time to the 3-day dietary regime. The great majority of blood samples were obtained before breakfast while the patient was fasting.

The analytic procedures employed are as follows: blood sugar, Folin (16); chloride, by Fiske and Lin's modified Volhard titration (17); creatine and creatinine, Folin (17) ; nitrogen, by micro Kjeldahl digestion, steam distillation, and titration; phosphorus, Fiske and Subbarow (18), modified for use with photoelectric colorimeter; potassium, Fiske and Litarazek (17) ; serum protein, using gradient tube of Jacobsen and Linderstr $\phi \mathrm{m}$-Lang (19) ; sodium, Butler and Tuthill (20) ; urea, Van Slyke (21) ; urinary 17-ketosteroids, Talbot, Berman, and MacLachlan (22).

\section{EXPERIMENTAL}

I. Observations on the body weight, nitrogen balance, carbohydrate metabolism, and 17-ketosteroid output. Figure 1 gives observations on the body weight and nitrogen balance of the patient over a period of 300 days. In the upper portion of the figure, the body weight in kilograms (solid circles) is plotted as the ordinate against time in days as the abscissa. The nitrogen balance in grams per day is represented by the checkered area according to the scale shown on the middle portion of the ordinate. Interruptions in the horizontal line, originating at zero on that scale, indicate periods when the nitrogen balance was not determined. At the bottom of the figure are horizontal lines representing the therapy. The upper, narrow, solid black line shows the 9 grams of sodium chloride added daily to the diet. The middle, wider, solid black line indicates intervals when $3 \mathrm{mgm}$. of desoxycorticosterone acetate were injected intramuscularly each day. The variously shaded areas at the bottom of the figure indicate the administration of other substances. The name and dose of each is printed immediately below the lower margin of the chart. Vertical lines extending from the bottom to the top of the chart show when changes in therapy occurred. The corresponding day of the total experimental session is given at the top of each vertical line. The individual experimental periods demarcated by these vertical lines are given numbers which appear half-way between the weight and nitrogen balance plots.

The figure shows that when, in addition to maintenance doses of desoxycorticosterone acetate and sodium chloride, methyl testosterone (periods $2,6,8,14$ ) or testosterone propionate (period 15) were given, there was a rapid gain in weight and an increased (positive) nitrogen balance, equal to a maximum of, respectively, 0.104 and 0.115 gram per $\mathrm{kgm}$. of body weight per day. During these periods, the patient appeared to be in excellent condition and to have more energy and endurance. Withdrawal of the testosterone therapy resulted in an initial loss of weight and of nitrogen (periods 3, 5, 9, 16). This "rebound phenomenon" was temporary (see period 9). Consequently, the weight and the nitrogen gained during testosterone therapy exceeded that lost after the therapy was discontinued. Anhydrohydroxy-progesterone (period 10) and methyl androstenediol (period 12), likewise induced nitrogen storage equal to a maximum of, respectively, 0.104 and 0.052 gram per $\mathrm{kgm}$. per day. However, these substances did not prompt an appreciable gain in weight. While the methyl androstenediol was being ingested, the patient's mouth became sore and she passed stools containing large quantities of mucous and probably lost more fecal nitrogen in this than in other periods. These symptoms disappeared shortly after administration of the drug was stopped. No 


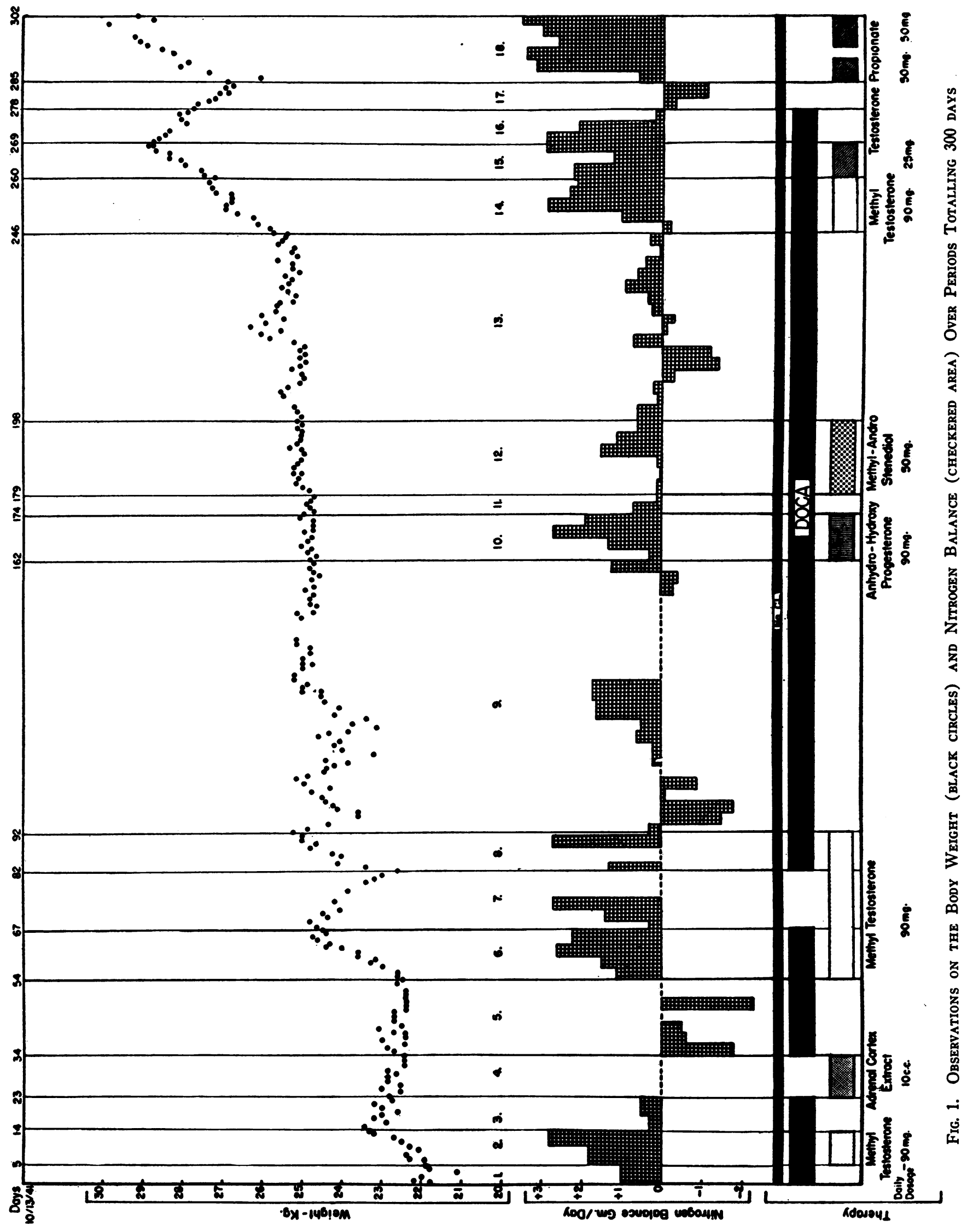


similar complaints developed while she was taking any of the other substances.

Though there was a temporary drop in the nitrogen balance on discontinuing the desoxycorticosterone acetate at the beginning of period 7 , the desoxycorticosterone per se did not appear to have any definite effect on the nitrogen balance. Except for this temporary drop in nitrogen balance during period 7 , both methyl testosterone and testosterone propionate had approximately the same influence on the nitrogen metabolism whether the patient was off or on desoxycorticosterone acetate therapy. However, although methyl testosterone caused an increase in body weight (periods 6 and 14) when administered with desoxycorticosterone acetate, it was incapable, during period 7 , of preventing a steady loss of body weight when the desoxycorticosterone acetate therapy was discontinued. At the end of 14 days, it became necessary to readminister desoxycorticosterone acetate (period 8 ) because by that time, the patient had lost $1.9 \mathrm{kgm}$. in weight and had developed symptoms of acute adrenal cortical insufficiency. On the other hand, under somewhat similar circumstances, testosterone propionate was found to be capable not only of preventing weight loss, but also of inducing a rapid weight gain (see periods 17 and 18 which are described in more detail below).

Measurements of the concentration of sugar in the blood obtained before breakfast and after a 12- to 15-hour fast were made from time to time during periods $2,3,6,7$, and 9 to 18 . The values obtained ranged between approximately 54 and $77 \mathrm{mgm}$. per cent, irrespective of the type of therapy administered. There was no evidence that either methyl testosterone or testosterone propionate had an appreciable influence on these fasting blood sugar levels.

During periods when the patient was receiving only sodium chloride, her urinary 17 -ketosteroid output ranged between 0.0 and $0.6 \mathrm{mgm}$. per day. Desoxycorticosterone acetate, methyl testosterone, and anhydro-hydroxy-progesterone therapy did not cause a rise in 17-ketosteroid output. On the other hand, approximately 50 per cent of the testosterone administered as testosterone propionate was recovered as urinary 17 -ketosteroids.

Comments. The results obtained with methyl testosterone and testosterone propionate while the patient was receiving desoxycortisterone acetate are in accordance with the observations of previous investigators on other types of patients who were not receiving desoxycorticosterone (23 to 25). The finding that desoxycorticosterone did not have an appreciable influence on the nitrogen balance is also in agreement with the literature (1). It was of interest to find that, while 100 mgm. per day of methyl testosterone could not prevent a loss of body weight when desoxycorticosterone was discontinued, $50 \mathrm{mgm}$. per day of testosterone propionate did cause a marked gain in body weight under similar circumstances. The information at hand is not sufficient to indicate whether the difference in effect resulted from differences in dosage or in pharmacologic action.

Although the methyl testosterone and the testosterone propionate had an apparently beneficial influence on the weight and nitrogen balance, their masculinizing effect in the course of a prolonged period of therapy might be undesirable. Therefore, an attempt was made to find substances which would induce nitrogen retention without promoting masculinization. Methyl androstenediol and anhydro-hydroxy-progesterone were selected for preliminary trial. The fact that the former had only a relatively small effect on the nitrogen balance and irritated the gastrointestinal tract does not recommend its clinical use. On the other hand, the results obtained with anhydrohydroxy-progesterone, which is an orally active progestational hormone (26), suggested that prolonged administration might result in a considerable retention of nitrogen. This substance is believed to have only slight masculinizing activity (26).

The present patient was known to be subject to attacks of hypoglycemia, ${ }^{3}$ a relatively common occurrence in individuals with Addison's disease. Therefore, the fact that the testosterone therapy did not result in a fall in fasting blood sugar

${ }^{3}$ Upon her first admission to the hospital, she had a blood sugar of $35 \mathrm{mgm}$. per cent and was having the convulsions of hypoglycemia. At a later date, after she had recovered from the Addisonian crisis, she was given an intravenous insulin tolerance test (27). Within $20 \mathrm{~min}$ utes, she lost consciousness and commenced to have convulsions. These evidences of insulin sensitivity and hypoglycemia unresponsiveness were elicited by a dose of insulin ( 0.025 units per $\mathrm{kgm}$.) which was only one-quarter that employed by Fraser et al. (27). 
TABLE I

Effect of changes in hormone therapy on body weight, serum $\mathrm{Na}$ and $\mathrm{K}$ concentrations, and urinary excretion

\begin{tabular}{|c|c|c|c|c|c|c|c|c|c|c|c|c|}
\hline \multicolumn{3}{|c|}{ Period } & \multirow{2}{*}{$\begin{array}{l}\text { Body** } \\
\text { weight }\end{array}$} & \multicolumn{2}{|c|}{ Serum* } & \multicolumn{7}{|c|}{ Average urine output per day } \\
\hline Number & Therapy & Length & & $\mathrm{Na}$ & $\mathbf{K}$ & $\mathrm{Na}$ & $\mathrm{Cl}$ & $\mathbf{k}$ & $\begin{array}{c}\text { Total } \\
\text { N }\end{array}$ & $\begin{array}{l}\text { Urea } \\
\mathbf{N}\end{array}$ & $\underset{\mathbf{N}}{\text { Creatinine }}$ & Creatine \\
\hline $\begin{array}{c}13 \\
\text { (fore- } \\
\text { period) }\end{array}$ & $\begin{array}{l}\mathrm{NaCl} \\
\mathrm{DOCA}\end{array}$ & $\begin{array}{r}\text { days } \\
9\end{array}$ & $\begin{array}{c}\text { grams } \\
25,500\end{array}$ & m. eq & 3.8 & 196 & $\begin{array}{l}\text { m. eq. } \\
206\end{array}$ & 47.9 & 6.61 & 5.31 & $\begin{array}{l}\text { grams } \\
0.135\end{array}$ & 0.028 \\
\hline 14 & $\begin{array}{l}\mathrm{NaCl} \\
\text { DOCA } \\
\text { Me-T }\end{array}$ & 14 & 27,360 & 144 & 2.9 & 188 & 211 & 40.8 & 5.29 & 3.55 & 0.172 & 0.024 \\
\hline 15 & $\begin{array}{l}\mathrm{NaCl} \\
\text { DOCA } \\
\text { T.P. }\end{array}$ & 9 & 28,860 & 147 & 1.9 & 199 & 220 & 38.2 & 4.83 & 3.17 & 0.191 & 0.019 \\
\hline 16 & $\begin{array}{l}\mathrm{NaCl} \\
\text { DOCA }\end{array}$ & 9 & 27,830 & 143 & 4.8 & 216 & 217 & 49.7 & 5.10 & 4.11 & 0.182 & 0.036 \\
\hline 17 & $\mathrm{NaCl}$ & 7 & 26,850 & 140 & 5.6 & 229 & 231 & 56.4 & 7.54 & 6.68 & 0.181 & 0.091 \\
\hline 18 & $\begin{array}{l}\mathrm{NaCl} \\
\text { T.P. }\end{array}$ & 17 & 29,590 & 140 & 0.7 & 169 & 201 & 44.5 & 4.11 & 3.31 & 0.167 & 0.007 \\
\hline 19 & $\mathrm{NaCl}$ & 3 & & 140 & 4.7 & & & & & & & \\
\hline
\end{tabular}

* Obtained on last day of each period.

values is not only of practical import but is also of theoretical interest because it fails to support the possibility that testosterone inhibits the formation of sugar from protein.

The low 17-ketosteroid output of this patient is of no diagnostic significance because of her age (28). The fact that no change occurred in the urinary 17 -ketosteroids following the administration of desoxycorticosterone, methyl testosterone, and anhydro-hydroxy-progesterone is in keeping with the findings of others ( 29 to 31 ). The 50 per cent recovery of testosterone propionate as urinary 17-ketosteroids corresponds to that found for normal children of the same age (32).

II. Observations on the effect of variations in therapy on potassium and nitrogen metabolism and body weight. Evidence of the literature suggests that the marked shifts in total body weight and in the nitrogen balance noted above might be accompanied by equally striking changes in electrolyte metabolism $(23,24,33)$. Such changes should be of particular interest in an Addisonian patient. Accordingly, during the latter portion of the investigation (periods 13 to 18 , Figure 1 ), measurements were made of the concentrations of sodium and potassium in the serum and of the urinary output of potassium, sodium, chloride, total and urea nitrogen, and creatine and creatinine (Table I). The recorded body weights and serum sodium and potassium concentrations are those obtained on the last day of each period. Intermediary measurements of these values were made, but are not recorded because they fall approximately on the curve described by the data given. The urinary output values represent the average daily output of each substance measured during the respective periods.

The data show that methyl testosterone and testosterone propionate caused the serum potassium concentration to fall to abnormally low levels (periods 14, 15, 18). This fall was associated with a diminution in urinary potassium and in both total and urea urine nitrogen excretion. Withdrawal of the testosterone therapy (periods 16, 19) resulted in a rise of the serum potassium to within normal limits (3.5 to 5.0 m.eq. per liter) and an increase in urinary potassium and total and urea nitrogen excretion. Withdrawal of the desoxycorticosterone acetate therapy (period 17) was followed by a rise in the serum potassium to the abnormally high concentration of 5.6 m.eq. per liter. At the same time, there was an increase in 
the urinary nitrogen and potassium excretion to above fore-period levels.

It will be remembered that methyl testosterone was unable to prevent the development of signs and symptoms of adrenal cortical insufficiency when desoxycorticosterone acetate therapy was withdrawn (period 7, Figure 1). The same was not true for testosterone propionate. At the end of period 17 (Figure 1, Table I), the patient had been off desoxycorticosterone acetate therapy for 8 days. As a consequence, she had lost $1.1 \mathrm{kgm}$. in weight and her blood pressure had fallen from $90 / 70$ to $70 / 40 \mathrm{~mm}$. $\mathrm{Hg}$. Her serum potassium had risen to $5.6 \mathrm{~m}$.eq. per liter and she had become listless, weak, and anorexic. On the basis of past experience with this patient, these symptoms and signs were interpreted as indicating acute adrenal cortical insufficiency. During the ensuing period 18, the patient was given $50 \mathrm{mgm}$. of testosterone propionate daily. Within 48 hours after this therapy had been started, she commenced to gain weight and all the aforementioned symptoms and signs disappeared, just as they had on previous occasions when desoxycorticosterone acetate had been given. Furthermore, in the course of the next 14 days, she had not only regained the weight lost, but $1.4 \mathrm{kgm}$. in addition. By the end of the period, her serum potassium had fallen to 0.7 m.eq. per liter. During this and preceeding periods when the serum potassium was abnormally low, the patient was up and about and showed no clinical evidences of muscular paralysis or weakness. Furthermore, there were no changes in the electrocardiogram which could be attributed to the testosterone therapy or low serum potassium values. ${ }^{4}$

4 Electrocardiograms, taken and interpreted by Dr. P. D. White's laboratory, at various times before, during, and after testosterone therapy, revealed that the $P-R$ interval was between 0.14 to 0.16 second (normal) but that the Q-T interval was always abnormally prolonged to between 0.38 and 0.45 second. Because the abnormalities in the electrocardiogram were noted before any testosterone therapy had been given, and at times when the serum potassium was normal ( $4.8 \mathrm{~m}$. eq. per liter), as well as at times when it was very abnormally low $(0.7 \mathrm{~m}$. eq. per liter), it is difficult to attribute the electrocardiographic changes to these factors. A similar prolongation of the $Q-T$ interval has been noted in adult Addisonian patients who were not receiving testosterone (14). It is also of interest that prolongation of the $Q-T$ interval is a
The testosterone did not have a pronounced effect on serum sodium concentrations, but appeared to cause a relative retention of sodium over chloride (periods $14,15,18$ ).

Comments. Perhaps the most novel of the changes noted above are the systematic fluctuations in serum potassium values with the administration and withdrawal of testosterone therapy. Similar fluctuations have been observed in other types of patients receiving testosterone (35). Hence, the changes in serum potassium concentrations observed here do not appear to be due to an idiosyncrasy in the present Addisonian patient.

In an attempt to visualize the metabolic effects of testosterone therapy and the possible mechanisms which might explain the fall in serum potassium, use has been made of the changes in body weight and in urinary excretion of nitrogen, potassium, sodium, and chloride. Since the urinary nitrogen excretion fluctuated but little and since the patient was in approximate nitrogen equilibrium during the latter part of the fore-period 13 (Figure 1), it has been assumed that a decrease or increase in urinary nitrogen below fore-period levels indicates, respectively, the daily retention or loss of a corresponding quantity of nitrogen within the body. As there was a similar constancy in the fore-period urinary potassium excretion, the same assumption has been made for potassium. If it is further postulated that the retained nitrogen is used for the formation of protoplasmic tissue such as muscle cells, then, since there are approximately 35 grams of nitrogen per kilo of true muscle, ${ }^{5}$ each gram of nitrogen retained indicates the formation of $1000 / 35$ or 28.6 grams of true muscle. ${ }^{6}$ Likewise, because true muscle con-

striking characteristic of patients suffering from such a hypocalcemia as this patient had (34).

5The term "true muscle" refers to fat-free, extracellular-water-free muscle fibres, collagen, and elastin (intracellular phase of Hastings and Eichelberger (36)).

6 According to Harrison, Darrow, and Yannet (37), monkey "true muscle" contains 314 grams of protein per liter of (intracellular) water. Since protein is 16 per cent nitrogen (37), such muscle contains $314 \times 0.16=$ 50 grams of nitrogen per liter of water. Monkey "true muscle" was also found to contain $143 \mathrm{~m}$. eq. of potassium per liter of intracellular water (37). Because (intracellular) water comprises approximately 70 per cent of true muscle $(36,37)$, the nitrogen per kilo of true muscle is $50 \times 0.70=35$ grams while the potassium per kilo of true muscle is $143 \times 0.70=100 \mathrm{~m}$. eq. Approxi- 
tains approximately 100 m.eq. of potassium ${ }^{6}$ per kilo, each m.eq. of potassium is representative of $1000 / 100$ or 10 grams of true muscle.

With this information, increments or decrements in true muscle may be calculated, both from changes in urinary nitrogen and from changes in urinary potassium excretion below or above foreperiod levels. ${ }^{7}$ For example, the data of Table I show that during period 14 , the patient gained nitrogen at the average rate of $6.61-5.29$ or 1.32 grams per day. Since the period was 14 days long, she gained a total of $1.32 \times 14$ or 18.5 grams of nitrogen and hence, $18.5 \times 28.6$ or $0.53 \mathrm{kgm}$. of muscle. Similarly, during the same period she gained a total of 99.5 m.eq. of potassium and hence $99.5 \times 10$ or $1 \mathrm{kgm}$. of muscle, or almost double the gain in muscle indicated by nitrogen. The total gain or loss of true muscle, thus estimated from both nitrogen and potassium, has been calculated for each period. Starting with the foreperiod as a baseline, the cumulative gains or losses in muscle and body weight at the end of each experimental period are plotted in Figure 2. Thus, the figure shows the changes which these calculations indicate as having occurred at the end of each period, in relation to the fore-period levels. In the figure, the body weight is represented by the upper solid horizontal lines, kilograms of true muscle calculated from urinary potassium by the interrupted horizontal lines, and kilograms of true muscle from urinary nitrogen by the shaded area. A scale in kilograms is given by the left-hand ordinate. The serum potassium concentration at the end of each experimental period is represented by black circles connected by a solid line, the scale in m.eq. per liter being along the right-hand ordinate.

It would appear from the pattern of Figure 2 that during periods 14 and 15 , when the patient was receiving $\mathrm{NaCl}$, desoxycorticosterone, and

mately equivalent values for muscle potassium are provided by the data of Katz (38) on humans and Hastings and Eichelberger (36) and Mellors, Muntwyler, and Mautz (39) on dogs.

7 Such excretion levels for nitrogen and potassium are known to be relatively stable (40) and not subject to the fluctuations of such excretion levels for sodium and chloride (40). Thus, the use of fore-period levels in estimating changes in intracellular balances is not subject to the errors involved in using this method to estimate extracellular fluid balances. methyl testosterone or testosterone propionate, the potassium retained was more than sufficient to meet the increased muscle tissue requirements, calculated from the nitrogen retention. Yet there was a progressive fall in serum potassium concentration during those two periods. Hence, it would appear that there was either an abnormal increase in intracellular potassium concentration, a retention of cell potassium to replace cell potassium lost during prolonged salt and DOCA therapy (41), or a marked increase in intracellular water with a resultant decrease in both intracellular and extracellular potassium concentrations. The latter possibility is favored by the fact that the weight gains in periods 14,15 , and 18 , Figure 2 , were more than sufficient to meet the gain in muscle tissue calculated from either nitrogen or potassium retention. It is also supported by the finding of Darrow and Miller that both desoxycorticosterone and testosterone cause a decrease in the potassium content of mammalian muscle (41). The fact that the urinary chloride excretion was increased in periods 14 and 15 and only slightly decreased in period 18 suggests that changes in extracellular fluid volume were not an important factor in the weight gains. This finding and the absence of any increase in urinary sodium do not support a replacement of cell sodium by potassium. In any case, it appears that testosterone creates a demand for intracellular potassium which must be met, even at the expense of extracellular potassium. This excess retention of intracellular water over that of nitrogen and potassium, suggested by the above interpretation of the data, may well reflect a physiologic characteristic of growing tissue (42). Withdrawal of testosterone therapy (period 16) was apparently followed by the immediate liberation of potassium from the muscle tissue and by an increase in urinary potassium and sodium, despite a continued increase in muscle tissue according to the nitrogen excretion data. This liberation of potassium without nitrogen, following withdrawal of testosterone therapy, has been observed by others $(23,24)$. Withdrawal of the desoxycorticosterone (period 17) resulted in the loss both of intracellular and extracellular water as judged by a loss of body weight, by negative nitrogen and potassium balances, and by an increase in the urinary chloride. A simultaneous increase in extracellular potassium concentration is 


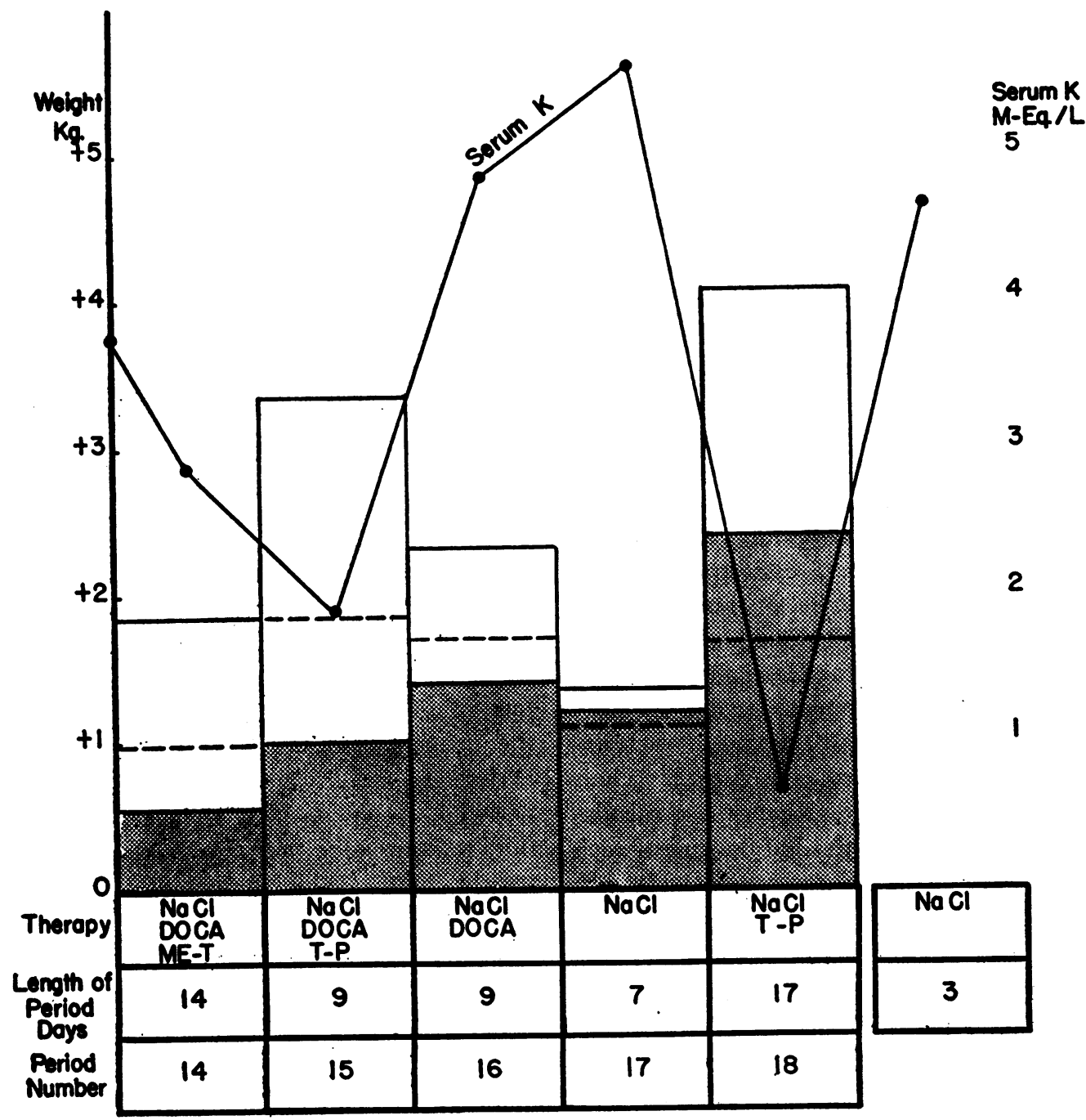

Fig. 2. Cumulative Gains or Losses in Body Weight (UPper solid horizontal lines) and Cell Tissue, Calculated from Urinary Potassium (interrupted horizontal lines) and from Urinary Nitrogen (shaded areas), at the End of Each Experimental Period in Relation TO FORE-PERIOD LEVELS

The scale in kilograms is given by the left-hand ordinate. The serum potassium concentration at the end of each experimental period is represented by the black circles connected by the solid line according to the scale along the right-hand ordinate. The abbreviations in the column corresponding to therapy have the following significance: $\mathrm{NaCl}$ sodium chloride; DOCA, desoxycorticosterone acetate; Me-T, methyl testosterone; and $\mathrm{T}-\mathrm{P}$, testosterone propionate.

evidenced by the rise in serum potassium concentration.

The administration of testosterone propionate alone (period 18) prompted a slightly different effect than that observed during periods 14 and 15 when testosterone was given with desoxycorticosterone. Nitrogen, potassium, chloride, and sodium were retained in significant quantities, but the quantity of potassium retained did not equal the theoretical requirements of the increased intracellular tissue, calculated from the nitrogen balance.

The relative increase in sodium retention above chloride with testosterone therapy would appear to be consistent either with an increase in the sodium-containing tissues such as bone, cartilage, 
and tendons $(37,43)$, or with an increase in muscle sodium such as was observed by Darrow and Miller following desoxycorticosterone (41). However, the intracellular tissue appeared to retain its priority for available potassium because the serum potassium fell to a remarkably low level.

The absence of muscular paralysis or weakness when the serum potassium concentration was abnormally low suggests strongly that a low serum potassium per se has little bearing on muscle contractility (35).

III. Observations on the calcium and phosphorus metabolism. As mentioned in the introduction, this patient with moniliasis was discovered to be suffering not only from Addison's disease, but also from idiopathic hypoparathyroidism. Numerous determinations of the serum calcium and phosphorus concentrations and the alkaline serum phosphatase activity were carried out during periods 13 to 18 . During these same periods, she was given sufficient doses of dihydrotachysterol to prevent severe hypocalcemia. Careful inspection of the data obtained did not reveal any relation between the dihydrotachysterol therapy or the serum calcium, phosphorus, and phosphatase values, respectively, and the changes in mineral or nitrogen metabolism, described in the preceeding paragraphs. Likewise, no relation appeared to exist between the desoxycorticosterone acetate or testosterone therapy and the disturbance in calcium and phosphorus metabolism. For these reasons, changes referable to the hypoparathyroidism will not be discussed here, but will be reported in a separate communication.

IV. Clinical observations on the effects of therapy. At the onset of the investigation (period 1), this 8-year-old patient appeared to be a thin, dark-complexioned, but otherwise normal appearing girl. She was $119 \mathrm{~cm}$. tall and weighed 22 $\mathrm{kgm}$. These values for height and weight were at the lower limit of normal, according to standards based on studies at the University of Iowa. Her intellectual, somatic, and secondary sexual development corresponded approximately to the average for a girl of her age. The skeletal development was also found to be normal for her age, according to Todd's standard roentgenograms of the hands.
During the 10-month period of study, she grew a total of $10 \mathrm{~cm}$. in height (average expected growth, $6.2 \mathrm{~cm}$.) and gained $7 \mathrm{kgm}$. in weight (average expected gain, $3.1 \mathrm{kgm}$.). Her appearance changed from that of a thin to that of a moderately plump girl. No peripheral or other edema was recognized at any time. The musculature appeared to increase in proportion to her increments in total body weight. The chestnutbrown hue of her skin became if anything slightly more intense. The voice became slightly bass. No moustache appeared, but a sparse growth of downy pubic hair developed. The breasts and nipples remained pre-adolescent in type, except during the period when she was receiving methyl androstenediol when a slight temporary mammary hyperplasia occurred. The clitoris underwent very slight hypertrophy. The skeletal development progressed so that it corresponded to the average normal for a girl of 11 years by the end of the investigation. Thus a 3-year advance in skeletal development had occurred during the course of 10 months.

The possibility that the adrenal cortical insufficiency, the hypoparathyroidism, and the moniliasis are related is intriguing. In this connection, it is of interest that the patient's brother after several years of moniliasis developed the signs of acute adrenal insufficiency. Moreover, Sutphin (44) informs us that he has observed moniliasis in two patients with "idiopathic" hypoparathyroidism.

\section{SUMMARY}

Clinical and metabolic studies of the effect of various hormones on an 8-year-old girl with moniliasis, Addison's disease, and idiopathic hypoparathyroidism are reported. These reveal that the administration of either methyl testosterone or testosterone propionate, in addition to maintenance doses of desoxycorticosterone acetate and sodium chloride, resulted in: (1) a gain in body weight; (2) a diminution in the urinary excretion of nitrogen, potassium, and sodium; and (3) a marked fall in the serum potassium concentration. No significant changes in fasting blood sugar concentrations were noted.

The administration of anhydro-hydroxy-progesterone or of methyl androstenediol, under similar circumstances, prompted a decrease in 
urinary nitrogen excretion but did not induce a prompt gain in body weight.

Methyl testosterone therapy did not prevent the development of symptoms and signs of acute adrenal cortical insufficiency when desoxycorticosterone acetate was withdrawn. On the other hand, testosterone propionate relieved the patient of all signs and symptoms of acute adrenal insufficiency after the discontinuation of desoxycorticosterone acetate therapy.

The marked lowering in the serum potassium concentration while the patient was receiving testosterone was not associated with clinical evidences of muscular weakness or paralysis. On the contrary, the patient seemed to benefit from the testosterone, as evidenced by gain in weight, growth in stature, and apparent increase in strength and endurance.

\section{BIBLIOGRAPHY}

1. Thorn, G. W., Howard, R. P., and Emerson, K., Jr., Treatment of Addison's disease with desoxycorticosterone acetate. J. Clin. Invest., 1939, 18, 449.

2. Thorn, G. W., Koepf, G. F., Lewis, R. A., and Olsen, E. F., Carbohydrate metabolism in Addison's disease. J. Clin. Invest., 1940, 19, 813.

3. Drury, D. R., Control of blood sugar. J. Clin. Endocrinol., 1942, 2, 421.

4. Burrill, M. W., and Greene, R. R., Androgen production in the female rat. The ovary and the adrenal in the immature rat. Endocrinology, 1941, 28, 871.

5. Looney, J. M., Sex factors of the adrenal gland. Endocrinology, 1940, 27, 511.

6. Papanicolaou, G. N., and Falk, E. A., A general muscular hypertrophy induced by androgenic hormone. Science, 1938, 87, 238.

7. Simonson, E., Kearns, W. M., and Enzer, N., Effect of oral administration of methyltestosterone on fatigue in eunuchoids and castrates. Endocrinology, 1941, 28, 506.

8. Gross, R. E., Neoplasms producing endocrine disturbances in childhood. Am. J. Dis. Child., 1940, 59, 579.

9. Callow, R. K., Significance of excretion of sex hormones in urine. Proc. Roy. Soc. Med., 1938, 31, 841.

10. Talbot, N. B., Butler, A. M., and Berman, R. A., Adrenal cortical hyperplasia with virilism: Diagnosis, course and treatment. J. Clin. Invest., 1942, 21, 559.

11. Fraser, R. W., Forbes, A. P., Albright, F., Sulkowitch, H., and Reifenstein, E. C., Jr., Colorimetric assay of $17-$ ketosteroids in urine. J. Clin. Endocrinology, 1941, 1, 234.
12. Butler, A. M., Ross, R. A., and Talbot, N. B., Probable adrenal insufficiency in an infant. J. Pediat., 1939, 15, 831.

13. Talbot, N. B., and Butler, A. M., Unpublished observations.

14. Thorn, G. W., Dorrance, S. S., and Day, E., Addison's disease: Evaluation of synthetic desoxycorticosterone acetate therapy in 158 patients. Ann. Int. Med., 1942, 16, 1053.

15. Thorn, G. W., Personal communication.

16. Folin, $O$., Micro method for the determination of blood sugar. New England J. Med., 1932, 206, 727.

17. Folin, O., Laboratory Manual of Biological Chemistry. D. Appleton Century Co., Inc., New York, 1934. 5th ed.

18. Fiske, C. H., and Subbarow, Y., The colorimetric determination of phosphorus. J. Biol. Chem., 1925, 66, 375.

19. Jacobsen, C. F., and Linderstrøm-Lang, K., Method for rapid determination of specific gravity. Acta Physiol. Scandinav., Vol. 2, Fasc. 2, p. 149, 1940.

20. Butler, A. M., and Tuthill, E., An application of the uranyl zinc acetate method for determination of sodium in biological material. J. Biol. Chem., 1931, 93, 171.

21. Van Slyke, D. D., Determination of urea by gasometric measurement of the carbon dioxide formed by the action of urease. J. Biol. Chem., 1927, 73, 695 .

22. Talbot, N. B., Berman, R. A., and MacLachlan, E. A., Elimination of errors in the colorimetric assay of neutral urinary 17-ketosteroids by means of a color correction equation. J. Biol. Chem., 1942, 143, 211.

23. Kenyon, A. T., Sandiford, I., Bryan, A. H., Knowlton, $\mathrm{K}$., and Koch, F. C., The effect of testosterone propionate on nitrogen, electrolyte, water and energy metabolism in eunuchoidism. Endocrinology, 1938, 23, 135.

24. Kenyon, A. T., Knowlton, K., Sandiford, I., Koch, F. C., and Lotwin, G., A comparative study of the metabolic effects of testosterone propionate in normal men and women and in eunchoidism. Endocrinology, 1940, 26, 26.

25. Albright, F.., Parson, W., and Bloomberg, E., Cushing's syndrome interpreted as hyperadrenocorticism leading to hypergluconeogenesis: results of treatment with testosterone propionate. J. Clin. Endocrinol., 1941, 1, 375.

26. Gaines, J. A., Geist, S. H., and Salmon, U. J., Value of pregneninolone in the treatment of functional uterine bleeding. J. Clin. Endocrinol., 1941, 1, 554.

27. Fraser, R., Albright, F., and Smith, P. H., The value of the glucose tolerance test, the insulin tolerance test, and the glucose-insulin tolerance test in the diagnosis of endocrinologic disorders of glucose metabolism. J. Clin. Endocrinol., 1941, 1, 297. 
28. Talbot, N. B., and Butler, A. M., Urinary 17-ketosteroid assays in clinical medicine. J. Clin. Endocrinol., 1942, 2, 724.

Talbot, N. B., Butler, A. M., Berman, R. A., Rodriguez, P. M., and MacLachlan, E. A., Excretion of 17-ketosteroids by normal and abnormal children. Am. J. Dis. Child., 1943, 65, 364.

29. Cuyler, W. K., Hirst, D. V., Powers, J. M., and Hamblen, E. C., Effects of desoxycorticosterone acetate on 17-ketosteroid and pregnanediol excretions. J. Clin. Endocrinol., 1942, 2, 373.

30. Hamblen, E. C., Cuyler, W. K., and Hirst, D. V., Studies of urinary excretion of progestin following oral administration of pregnen-in-on-3-ol-17 (anhydro-hydroxy-progesterone). Endocrinology, 1940, 27, 35.

31. Wilkins, L., Fleischmann, W., and Howard, J. E., Effects of various androgens on sexually immature dwarfs. Paper read before the American Pediatric Society, May 2, 1942.

32. Talbot, N. B., Unpublished observations.

33. Thorn, G. W., and Engel, L. L., The effect of sex hormones on the renal excretion of electrolytes. J. Exper. Med., 1938, 68, 299.

34. Graybiel, A., and White, P. D., Electrocardiography in Practice. W. B. Saunders Co., Philadelphia, 1941.

35. Butler, A. M., Talbot, N. B., and MacLachlan, E. A., The effect of testosterone therapy on the concentration of potassium in serum. Proc. Soc. Exper. Biol. and Med., 1942, 51, 378.

36. Hastings, A. B., and Eichelberger, L., The exchange of salt and water between muscle and blood. I. The effect of an increase in total body water produced by the intravenous injection of isotonic salt solutions. J. Biol. Chem., 1937, 117, 73.

37. Harrison, H. E., Darrow, D. C., and Yannet, H., The total electrolyte content of animals and its probable relation to the distribution of body water. $\mathrm{J}$. Biol. Chem., 1936, 113, 515.

38. Katz, J., Die mineralischen Bestandtheile des Muskelfleishes. Pflugers Arch. f. d. ges. Physiol., 1896, 63, 1.

39. Mellors, R. C., Muntwyler E., and Mautz, F. R., Electrolyte and water exchange between skeletal muscle and plasma in the dog following acute and prolonged extracellular electrolyte loss. J. Biol. Chem., 1942, 144, 773.

40. Gamble, J. L., Chemical Anatomy, Physiology and Pathology of Extracellular Fluid. A Lecture Syllabus. Spaulding-Moss, Boston, 1942. 4th printing.

41. Darrow, D. C., and Miller, H. C., The production of cardiac lesions by repeated injections of desoxycorticosterone acetate. J. Clin. Invest., 1942, 21, 601.

42. Talbot, N. B., Lowry, O. H., and Astwood, E. B., Influence of estrogen on the electrolyte pattern of the immature rat uterus. J. Biol. Chem., 1940, $132,1$.

43. Hastings, A. B., The electrolytes of tissues and body fluids. Harvey Lectures, 1940-1941, Series 36, pages 91-125.

44. Sutphin, A., Personal communication. 